\title{
PENGARUH PENDIDIKAN KESEHATAN TERHADAP PERILAKU REMAJA TENTANG SADARI DI SMP NEGRI 29 SEMARANG
}

\author{
Oleh: \\ Sitti Umu Nasibah ${ }^{1}$, Anita Indra ${ }^{2}$, Putri Kusuma Wardhani ${ }^{3}$ \\ Program Studi D IV Bidan Pendidik STIKES Karya Husada Semarang
}

Email: nasibah_ummu@yahoo.co.id

\begin{abstract}
ABSTRAK
Latar Belakang : Sadari (Periksa Payudara Sendiri) merupakan usaha untuk mendapatkan kanker payudara pada stadium yang lebih dini. Pendidikan kesehatan adalah suatu upaya atau kegiatan untuk menciptakan perilaku masyarakat yang kondusif untuk kesehatan Dari studi pendahualuan di SMP Negri 29 Semarang dari 6 siswi 2 diantaranya melakukan sadari. Tujuan : Mengetahui apakah ada pengaruh pendidikan kesehatan terhadap perilaku remaja tentang sadari di smp negri 29 semarang. Metode Penelitian : Penelitian ini menggunakan jenis penelitian kuantitatif, dengan pendekatan Quasi Eksperimen (Two group pre-test and posttest). Populasi penelitian ini adalah 137 siswi SMP kelas IX dan sampel penelitian sebanyak 102 siswi dengan teknik stratified random sampling. Data yang di peroleh di olah menggunakan wilcoxon dan mann withney. Hasil Penelitian : Hasil penelitian yang telah di lakukan di SMP Negri 29 Semarang di peroleh hasil ada pengaruh pendidikan kesehatan terhadap perilaku remaja tentang sadari di SMP Negri 29 Semarang dengan $p$ value $0,000(\mathrm{p}<0,05)$. Kesimpulan : ada pengaruh pendidikan kesehatan terhadap perilaku remaja tentang sadari di SMP Negri 29 Semarang dengan $p$ value $0,000(\mathrm{p}<0,05)$.
\end{abstract}

Kata kunci : Metode Demonstrasi; Remaja; Sadar; Pendidikan kesehatan; Perilaku.

Pustaka : 20 (2007-2015)

\section{THE EFFECTIVENESS OF HEALTH EDUCATION ON ADOLESCENT BEHAVIOR OF BSE IN JUNIOR HIGH SCHOOL STATE OF 29 SEMARANG}

\begin{abstract}
Background Of The Research : BSE (breast self examination) is an attempt to get breast cancer at earlier stages of disease. Health education is an effort or activity to create a community behavior conducive to health. From preliminary studies At junior high school state of 29 semarang of 6 girls 2 of them has done a breast selfexamination (BSE). Objectives Of The Research : To find out the effectiveness of health education on adolescent behavior of bse in smp negri 29 semarang. Method Of The Research : This research used a quantitative research, with quasy experimental design (Two group pre-test ang post-test). The population of thie research is one hundred and trirty seven students grad IX of smp negri 29 semarang. While, the research used stratified random sampling technic to take the one hundred and two population as sample. The researcher used wilcoxon and mann wihtney assessment to analise the data. Result Of The Research : After had done a research in junior high school state of 29 semarang, the research got the result there is effectiveness of health education on adolescent behavior of BSE in junior high school state of 29 semarang with $p$ value $0,000(\mathrm{p}<0,05)$. Conclusion : Hopefully, the school can work together with agencies such as health centers to hold additional knowledge of knowing by providing extension by resource related.
\end{abstract}

Keywords : Adolescent; Behavior; BSE; Health Education; Methods Lecture. 


\section{Pendahuluan}

Sadari (Periksa Payudara Sendiri) merupakan usaha untuk mendapatkan kanker payudara pada stadium yang lebih dini (down staging). Diperlukan pelatihan yang baik dan evaluasi yang reguler. Sadari direkomendasikan dilakukan setiap bulan, 7 hari setelah menstruasi bersih. ${ }^{[6]}$

Kanker payudara di Indonesia merupakan penyebab kematian nomor dua setelah kanker mulut rahim, kanker payudara banyak menyerang wanita yang telah berumur lebih dari 40 tahun. Sistem Informasi Rumah Sakit (SIRS) di Indonesia tahun 2007 diketahui bahwa kanker payudara menempati urutan pertama pasien rawat inap 16,85\% dan pasien rawat jalan 21,69\% Berdasarkan penelitian yang dilakukan oleh Oemiati, dkk, (2011) prevalensi kasus tumor di Indonesia sebanyak 5,03 \%. Provinsi tertinggi yaitu Yogyakarta 9,66\% dan Jawa Tenggah 8,06\%. Menurut jenis dan lokasi tumor, kanker payudara menunjukan nilai risiko $15,6 \%$. $^{[1]}$

Jumlah kasus kanker payudara di Provinsi Jawa Tengah baik kasus baru maupun lama pada tahun 2011 sebanyak 910 kasus, tahun 2012 sebanyak 1781 kasus dan tahun 2013 sebanyak 4077 kasus. tahun 2014 sebanyak 512 kasus, tahun 2015 sebanyak 1469 kasus. Kejadian kanker payudara mengalami kenaikan setiap tahun. Jika dibandingkan dengan kanker jenis lain kanker payudara menduduki peringkat pertama dengan jumlah kasus terbanyak $44,9 \%$. $^{[2]}$

Jumlah kasus kanker payudara di kota semarang pada tahun 2013 sebanyak 1.205 kasus kanker payudara dan pada tahun 2014 terdapat 4.306 kasus kanker payudara dan pada tahun 2015 berjumlah 897 kasus kanker payudara yang terdiri dari criteria remaja berumur 11-24 tahun ada 28 orang, sedangkan pada usia 25-44 berjumlah 400 orang dan pada usia 45 tahun keatas terdapat 451 orang penderita kanker payudara.dari angka kejadian kanker pada tahun 2013-2014 mengalami peningkatan drastic yakni bertambah 3.101 kasus dan pada tahun 2015 mengalami penurunan. ${ }^{[2]}$

Berdasarkan studi pendahuluan yang didapatkan, bahwa dari 6 siswa hanya 2 orang saja yang pernah melakukan sadari walaupun tidak mengetahui manfaatnya, sehingga peneliti tertarik untuk meneliti mengenai "Pengaruh Pendidikan Kesehatan Terhadap Perilaku Remaja Tentang Sadari Di SMPN 29 Semarang”. 


\section{Tinjauan Teoritis}

Pendidikan kesehatan adalah proses untuk meningkatkan kemampuan masyarakat dalam memelihara dan meningkatkan kesehatannya. Tujuan pendidikan adalah mengembangkan atau meningkatkan 3 domain perilaku yaitu kognitif (cognitive domain), afektif (affective domain), dan psikomotor (psychomotor domain). ${ }^{[3]}$

Metode demonstrasi adalah metode mengajar dengan cara memperagakan barang, kejadian, aturan, dan urutan melakukan suatu kegiatan, baik secara langsung maupun melalui penggunaan media pengajaran yang relevan dengan pokok bahasan atau materi yang sedang disajikan. Tujuan pengajaran menggunakan metode demonstrasi adalah untuk memperlihatkan proses terjadinya suatu peristiwa sesuai materi ajar, cara pencapaiannya dan kemudahan untuk dipahami oleh siswa dalam pengajarn kelas. Metode demonstrasi mempunyai beberapa kelebihan dan kelekurangan. ${ }^{[4]}$

Masa remaja adalah masa transisi yang ditandai oleh adanya perubahan fisik, emosi dan psikis. Masa remaja, yakni antara usia 10-19 tahun, adalah suatu periode masa pematangan organ reproduksi manusia, dan sering disebut masa pubertas. Dalam tahapan perkembangan remaja menempati posisi setelah masa anak dan sebelum masa dewasa. Adanya perubahan besar dalam tahap perkembangan remaja baik perubahan fisik maupun perubahan psikis (pada perempuan setelah mengalami menarche dan pada laki-laki setelah mengalami mimpi basah) menyebabkan masa remaja relatif bergejolak dibandingkan dengan masa perkembangan lainnya. Hal ini menyebabkan masa remaja menjadi penting untuk diperhatikan. Berdasarkan tahapan perkembangan individu dari masa bayi hingga masa tua akhir menurut Erickson, masa remaja dibagi menjadi tiga tahapan yakni masa remaja awal, masa remaja pertengahan, dan masa remaja akhir. Adapun kriteria usia masa remaja awal pada perempuan yaitu 13-15 tahun dan pada laki-laki yaitu 15-17 tahun. Kriteria usia masa remaja pertengahan pada perempuan yaitu 15-18 tahun dan pada laki-laki yaitu 17-19 tahun. Sedangkan kriteria masa remaja akhir pada perempuan yaitu 18-21 tahun dan pada laki-laki 19-21 tahun Laki-laki lebih lambat matang daripada anak perempuan, maka laki-laki mengalami periode awal masa remaja yang lebih singkat, meskipun pada usia 18 tahun ia telah dianggap dewasa, seperti halnya anak perempuan. Akibatnya, seringkali laki-laki 
tampak kurang untuk usianya dibandingkan dengan perempuan. Namun adanya status yang lebih matang, sangat berbeda dengan perilaku remaja yang lebih muda. Batasan usia remaja menurut WHO adalah 12 sampai 24 tahun. Menurut Depkes RI adalah antara 10 samapi 19 tahun dan belum kawin. Menurut BKKBN adalah 10 sampai 19 tahun ${ }^{[5]}$

Sadari (Periksa Payudara Sendiri) merupakan usaha untuk mendapatkan kanker payudara pada stadium yang lebih dini (down staging). Tujuan dari pemeriksaan payudara sendiri adalah untuk mendeteksi secara dini gejala kanker payudara secara individu. Masih banyak wanita yang belum menyadari pentingnya mereka melakukan pemeriksaan dini terhadap payudaranya. Dalam kenyataan sehari - hari banyak wanita datang ke dokter setelah mereka menyadari adanya benjolan yang terus membesar dan dibiarkan saja, dengan alasan ekonomi, khawatir harus dioperasi. Alasan keuangan yang tidak memadai, membuat mereka enggan memeriksakan diri ke dokter. Namun, beberapa wanita yang peduli dengan kesehatan payudaranya memeriksakan payudaranya sejak dini ke dokter atas kesadaran mereka sendiri. [6]

Prilaku adalah respon individu terhadap suatu stimulus atau suatu tindakan yang dapat diamati dan mempunyai frekuensi spesifik, durasi dan tujuan baik disadari maupun tidak. Perilaku kesehatan adalah suatu respon seseorang (organisme) terhadap stimulus yang berkaitan dengan sakit dan penyakit, sistem pelayanan kesehatan, makanan serta lingkungan Meskipun perilaku adalah bentuk proses atau reaksi terhadap stimulus atau rangsangan dari luar organisme (orang), namun dalam memberikan respon sangat tergantung pada karakteristik atau faktor-faktor dari orang yang bersangkutan. ${ }^{[7]}$

\section{Metode Penelitian}

\section{A. Jenis dan Desain Penelitian}

Jenis penelitian yang digunakan adalah penelitian kuantitatif dengan desain eksperimen semu (quasi experiment) yaitu desain yang bertujuan untuk mencari hubungan sebab akibat dan mengungkapkan adanya pengaruh keterlibatan peneliti dalam perlakuan (intervensi) yang akan mengakibatkan perubahan-perubahan yang terjadi setelah perlakuan pada variabel penelitian (Nursalam, 2008). Observasi tingkat nyeri (variabel terikat) dilakukan dengan teknik "Pre-Test and Post-Test One Group Design", artinya observasi dilakukan sebanyak dua kali pada satu kelompok eksperimen, yaitu observasi 
sebelum treatment diberikan (Pre Test) dan observasi setelah dilakukan treatment (PostTest). ${ }^{[8]}$

Populasi yang diambil dalam penelitian ini adalah semua remaja putri kelas IX yang total ada 8 kelas di SMP Negeri 29 Semarang sebanyak 137 siswi remaja putri.Sampel penelitian ini adalah 102 siswi putri kelas IX di SMP Negeri 29 Semarang tahun 2017. Variable yang akan di teliti adalah perilaku ramaja tentang sadari.

Teknik sampling yang digunakan adalah Proportionate Stratified Random Sampling, yaitu dimana semua individu mempunyai kesempatan yang sama terpilih sebagai sampel. Penentuan sampel dengan cara menggunakan sistem acak. ${ }^{[8]}$

Uji normalitas data dilakukan dengan menggunakan kolmogorof sminof karena sampel lebih dari 50 orang. Pengolahan data berditribusi tidak normal dan berpasangan menggunakan wilcoxon. Pengolahan data berdistribusi tidak normal dan tidak berpasangan menggunakan Mann Whithney.

\section{Hasil Penelitian}

\section{Univariat}

a. Perilaku responden sebelum di berikan pendidikan kesehatan tentang sadari dengan metode ceramah di SMPN 29 semarang pada kelompok kontrol dan kelompok eksperimen

Hasil perilaku sebelum dilakukan pendidikan kesehatan pada kelompok eksperimen di peroleh rata-rata (mean) 1,35 dengan nilai Median sebesar 1,00, nilai standar deviasi sebesar 483, dan perilaku tertinggi adalah 2 terendah adalah 1.

Hasil perilaku sesudah dilakukan pendidikan kesehatan pada kelompok eksperimen di peroleh rata-rata (mean) 1,94 dengan nilai Median sebesar 2,00, nilai standar deviasi sebesar 238, dan perilaku tertinggi adalah 2 terendah adalah 1.

b. Perilaku responden sesudah di lakukan pendidikan kesehatan tentang sadari dengan metode ceramah di SMPN 29 semarang pada kelompok kontrol dan kelompok eksperimen. 
Hasil perilaku sebelum dilakukan pendidikan kesehatan pada kelompok eksperimen di peroleh rata-rata (mean) 1,25 dengan nilai Median sebesar 1,00, nilai standar deviasi sebesar 440, dan perilaku tertinggi adalah 2 terendah adalah 1.

Hasil perilaku sebelum dilakukan pendidikan kesehatan pada kelompok eksperimen di peroleh rata-rata (mean) 1,24 dengan nilai Median sebesar 1,00, nilai standar deviasi sebesar 428, dan perilaku tertinggi adalah 2 terendah adalah 1.

\section{Bivariat}

Dari hasil uji beda pada perilaku sebelum dan sesudah pendidikan kesehatan tentang sadari pada kelompok eksperimen didapatkan rata-rata 18,50. Oleh karena $p$ value $0,000(\mathrm{p}<0,05)$ maka Ha diterima yang berarti bahwa terdapat perbedaan perilaku sebelum dan sesudah pendidikan kesehatan tentang sadari pada kelompok eksperimen di SMP Negri 29 Semarang secara bermakna.

Dari hasil uji beda pada perilaku sebelum dan sesudah pendidikan kesehatan tentang sadari pada kelompok kontrol didapatkan rata-rata 11,00. Oleh karena $p$ value $0,827(\mathrm{p}<0,05)$ maka $\mathrm{H} 0$ diterima yang berarti bahwa tidak terdapat perbedaan perilaku sebelum dan sesudah pendidikan kesehatan tentang sadari pada kelompok kontrol di SMP Negri 29 Semarang secara bermakna.

Berdasarkan hasil penelitian perilaku pada 51 siswi kelompok kontrol dan 51 siswi kelompok kontrol diketahui bahwa terdapat nilai sig ( 2 taled) sebesar $.819>0,05$ hal ini berarti H0 diterima sehingga tidak terdapat pengaruh pendidikan kesehatan terhadap perilaku remaja tentang sadari di SMP Negri 29 Semarang secara bermakna.

Berdasarkan hasil penelitian perilaku pada 51 siswi kelompok eksperimen dan 51 siswi kelompok eksperimen diketahui bahwa terdapat nilai sig ( 2 taled) sebesar 0,000< 0,05 , hal ini berarti Ha diterima sehingga terdapat pengaruh pendidikan kesehatan terhadap perilaku remaja tentang sadari di SMP Negri 29 Semarang secara bermakna.

\section{Pembahasan}

A.

\section{Analisis univariat}

Hasil perilaku sebelum dilakukan pendidikan kesehatan pada kelompok eksperimen di peroleh rata-rata (mean) 1,35 dengan nilai Median sebesar 1,00, nilai standar deviasi sebesar 483, dan perilaku tertinggi adalah 2 terendah adalah 1 . Hasil 
perilaku sebelum dilakukan pendidikan kesehatan pada kelompok kontrol di peroleh ratarata (mean) 1,24 dengan nilai Median sebesar 1,00, nilai standar deviasi sebesar 428, dan perilaku tertinggi adalah 2 terendah adalah 1 . hasil uji memiliki hasil kelompok kontrol tidak ada peningkatan mean sebelum dan sesudah dilakukan pengajaran artinya tidak ada pengaruh pada kelompok kontrol.

Hasil perilaku sesudah dilakukan pendidikan kesehatan pada kelompok eksperimen di peroleh rata-rata (mean) 1,94 dengan nilai Median sebesar 2,00, nilai standar deviasi sebesar 238, dan perilaku tertinggi adalah 2 terendah adalah 1 . Artinya ada kenaikan perilaku sebelum dan sesudah pendidikan kesehatan, sebelum di berikan pendidikan kesehatan nilai rata-rata (mean) 1,35 dan setelah di berikan pendidikan kesehatan ada kenaikan yakni 1,94 .

\section{B. Analisis Bivariat}

Hasil uji beda sebelum dan sesudah pendidikan kesehatan pada kelompok eksperimen didapatkan rata-rata 18,50 dengan $p$ value $0,000(\mathrm{p}<0,05)$. Hal ini dapat disimpulkan terdapat perbedaan hasil perilaku sebelum dan sesudah pada kelompok eksperimen. Pada pembelajaran dengan metode demonstrasi yang mana yang belangsung dengan cara memperagakan barang, kejadian, aturan, dan urutan melakukan suatu kegiatan, baik secara langsung maupun melalui penggunaan media pengajaran yang relevan dengan pokok bahasan atau materi yang sedang disajikan, sehingga siswa dapat menyaksikan langsung apa yang sedang di jelaskan. ${ }^{[4]}$

Hasil uji beda sebelum dan sesudah pendidikan kesehatan pada kelompok eksperimen didapatkan rata-rata 11,00 dengan $p$ value 0,827 ( $\mathrm{p}>0,05$ ). Hal ini dapat disimpulkan tidak terdapat perbedaan hasil perilaku sebelum dan sesudah pada kelompok kontrol. Tidak ada peningkatan perilaku sebelum dan sesudah pendidikan kesehatan pada siswi IX di SMP Negri 29 Semarang pada kelompok kontrol. Hal ini bisa terjadi karna karna pada kelompok control tidak di berikan perlakuan seperti pendidikan kesehatan mengenai sadari sehingga tidak ada peningkatan pengetahuan yang dapat mempengaruhi perilaku siswa. ${ }^{[4]}$

Pada penelitian ini diperoleh hasil bahwa pendidikan kesehatan dapat memberikan pengaruh terhadap peningkatan perilaku siswi tentang sadari di SMP Negri 29 Semarang dengan hasil $p$ value $0.000<0,05$. Jadi secara segnifikan pendidikan kesehatan dapat meningkatkan perilaku. Hal ini dapat terjadi karna pemberian pendidikan kesehatan yang di lakukan selama 30 menit yang mana di dalam pendidikan kesehatan tersebut di jelaskan 
mengenai remaja dan juga sadari yang meliputi : pengertian, tujuan, dan teknik melakukan sadari. Dan dilakukan juga pemberian video stimulus tentang sadari setelah materi selesai melakukan praktek cara melakukan sadari. ${ }^{[4]}$

\section{Kesimpulan}

1. Hasil perilaku sebelum dilakukan pendidikan kesehatan terhadap perilaku remaja tentang sadari untuk kelompok kontrol yaitu 1,25 dan pada kelompok eksperiment yaitu 1,35.

2. Hasil perilaku sesudah dilakukan pendidikan kesehatan terhadap perilaku remaja tentang sadari untuk kelompok kontrol yaitu 1,27 dan pada kelompok eksperiment yaitu 2,00.

3. Hasil uji beda sebelum dan sesudah pendidikan kesehatan pada kelompok eksperimen disimpulkan terdapat perbedaan hasil perilaku sebelum dan sesudah pada kelompok eksperimen dengan $p$ value 0,000 .

4. Hasil uji beda sebelum dan sesudah pendidikan kesehatan pada kelompok kontrol disimpulkan tidak terdapat perbedaan hasil perilaku sebelum dan sesudah pada kelompok control $p$ value 0,835 .

5. Ada pengaruh pengaruh pendidikan kesehatan terhadap perilaku remaja tentang sadari di SMP Negri 29 Semarang secara bermakna dengan $p$ value 0,000 .

\section{Saran}

1. Bagi siswi

Agar melakukan pemeriksaan sadari setiap bulannya yang dapat mendeteksi dini kanker payudara secara individu.

2. Bagi Sekolah SMP N 29 Semarang

Agar mengadakan tambahan pengetahuan tentang sadari dengan mengadakan penyuluhan oleh narasumber yang berkaitan dan mendirikan UKS atau lebih mempergunakan UKS di sekolah.

3. Bagi Institusi Pendidikan

Untuk mengadakan praktek yang bersangkutan dengan sadari di instansi pendidikan, sehingga kesadaran mengenai sadari dapat di tingkatkan. 
4. Bagi Peneliti Selanjutnya

Agar dapat menambahkan metode pembelajaran yang lainnya, atau melakukan penelitian dengan dua metode dengan dua group pre dan post test sehingga dapat membandingkan keefektifan metode tersebut.

\section{Daftar Refensi}

[1] Kementerian Kesehatan RI. 2010. Rencana Strategis Kementerian Kesehatan Tahun 2010-2014. Jakarta: Kementrian Kesehatan RI.

[2] Dinkes Jateng. 2015. Profil Kesehatan Provinsi Jawa Tengah. Semarang: Dinkes Jateng.

[3] Notoatmodjo, S. 2010. Metodologi Penelitian Kesehatan. Jakarta: Rineka Cipta.

[4] Muhibbin Syah.2010.Psikologi Pendidikan dengan pendekatan baru. Bandung:PT Remaja Rosdakarya

[5] Widyastuti, Rahmawati, Purnamaningrum. 2009. Kesehatan Reproduksi. Yogyakarta: Fitramaya.

[6] Manuaba, IBG, dkk. 2010. Ilmu Kebidanan Penyakit Kandungan Dan KB. Jakarta: EGC.

[7] Wawan, A dan Dewi, M. 2010. Teori dan Pengukuran Pengetahuan, Sikap dan Perilaku Manusia. Yogyakarta : Nuha Medika.

[8] Sugiyono. 2010. MetodePenelitian Kualitatif \& RND. Bandung : Alfabeta. 